\title{
Corrigendum: Antibacterial activities of bacteriocins: application in foods and pharmaceuticals
}

\author{
Shih-Chun Yang ${ }^{1,2,3}{ }^{+}$, Chih-Hung Lin ${ }^{4,5}+$, Calvin T. Sung ${ }^{6}$ and Jia-You Fang ${ }^{1,2,7 *}$ \\ ${ }^{1}$ Research Center for Industry of Human Ecology, Chang Gung University of Science and Technology, Taoyuan, Taiwan \\ 2 Pharmaceutics Laboratory, Graduate Institute of Natural Products, Chang Gung University, Taoyuan, Taiwan \\ ${ }^{3}$ Chang Gung Memorial Hospital, Taoyuan, Taiwan \\ ${ }^{4}$ Center for General Education, Chang Gung University of Science and Technology, Taoyuan, Taiwan \\ ${ }^{5}$ Chronic Diseases and Health Promotion Research Center, Chang Gung University of Science and Technology, Taoyuan, Taiwan \\ ${ }^{6}$ Department of Microbiology, Immunology, and Molecular Genetics, University of California, Los Angeles, Los Angeles, CA, USA \\ ${ }^{7}$ Chinese Herbal Medicine Research Team, Healthy Aging Research Center, Chang Gung University, Taoyuan, Taiwan \\ ${ }^{*}$ Correspondence: fajy@mail.cgu.edu.tw \\ these authors have contributed equally to this work.
}

Edited and reviewed by:

Eva-Guadalupe Lizárraga-Paulín, Instituto Tecnológico y de Estudios Superiores de Monterrey, Mexico

Keywords: bacteriocin, protein, natural product, food, cancer treatment

\section{A corrigendum on}

Antibacterial activities of bacteriocins: application in foods and pharmaceuticals by Yang, S.-C., Lin, C. H., Sung, C. T., and Fang, J.-Y. (2014). Front. Microbiol. 5:241. doi: 10.3389/fmicb.2014. 00241

An additional affiliation of "Chang Gung Memorial Hospital, Kweishan, Taoyuan,
Taiwan" was attached for Shih-Chun Yang.

Conflict of Interest Statement: The authors declare that the research was conducted in the absence of any commercial or financial relationships that could be construed as a potential conflict of interest.

Received: 13 October 2014; accepted: 20 November 2014; published online: 05 December 2014.

Citation: Yang S-C, Lin C-H, Sung CT and Fang J-Y (2014) Corrigendum: Antibacterial activities of bacteriocins: application in foods and pharmaceuticals. Front. Microbiol. 5:683. doi: 10.3389/fmicb.2014.00683 This article was submitted to Food Microbiology, a section of the journal Frontiers in Microbiology.

Copyright () 2014 Yang, Lin, Sung and Fang. This is an open-access article distributed under the terms of the Creative Commons Attribution License (CC BY). The use, distribution or reproduction in other forums is permitted, provided the original author(s) or licensor are credited and that the original publication in this journal is cited, in accordance with accepted academic practice. No use, distribution or reproduction is permitted which does not comply with these terms. 